\title{
The Future of Harmful Algal Blooms in Florida Inland and Coastal Waters ${ }^{1}$
}

\author{
Karl Havens ${ }^{2}$
}

\section{Summary}

Algal blooms are common in Florida lakes, reservoirs, rivers, and estuaries. Sometimes blooms are beneficial. They are comprised of algae that provide essential food for shellfish and microscopic animals in the water, which in turn are eaten by fish. They also feed oysters, which build reefs that provide essential habitat.

Sometimes, blooms can become harmful and inhibit human recreational uses of the water or impair the ecosystem. Harmful algal blooms are stimulated by excessive levels of nutrients and also by warm water. There is evidence that harmful algal blooms will become more severe and more difficult to control in the future because of warming caused by climate change.

\section{What are algal blooms?}

When microscopic algae, or phytoplankton, found in rivers, lakes, reservoirs, estuaries, and the ocean, grow to levels that are considerably higher than the average, this is called a bloom.

Blooms become a concern when they reach excessive levels and are comprised of kinds of algae that are inedible, produce toxic chemicals, or produce nasty odors when they decompose. These harmful algal blooms, also known as HABs, can cause fish kills and impact other animals and plants in a water body, and they can adversely affect recreational uses of the water. Some of the algae that form HABs can cause skin and respiratory irritation, further impacting swimming, boating, and fishing. HABs also are unsightly and create odors when they die, and therefore have the potential to lower waterfront property values. Imagine a person trying to sell a house with green slime on the waterfront and washed up on the shoreline (Figure 1).

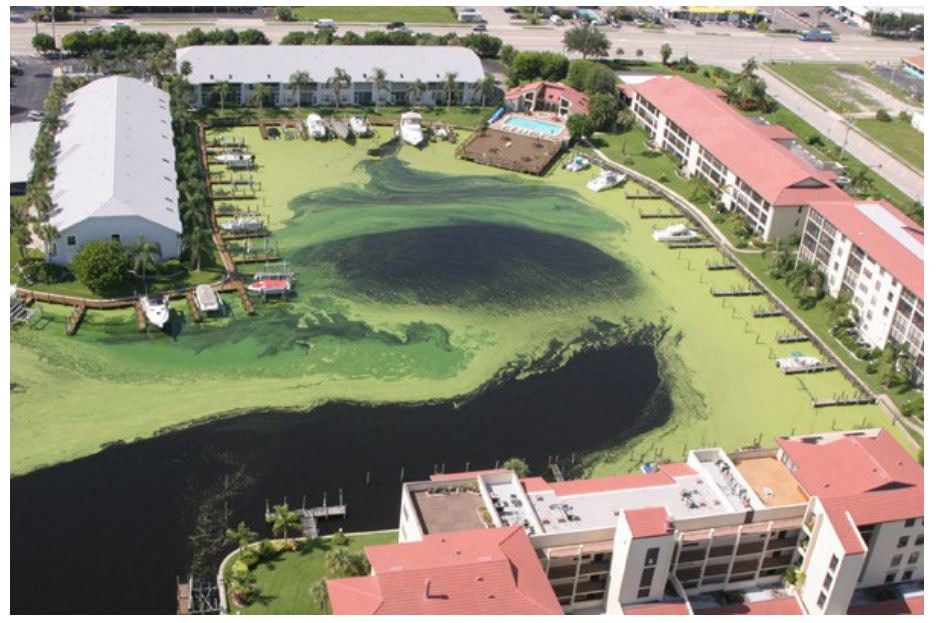

Figure 1. A photo from the air shows dense algae on the water surface along the shoreline of waterfront properties.

Credits: Environmental Protection Agency

In lakes and reservoirs, the most common kind of algae that produce HABs are blue-green algae, also known as cyanobacteria. There are several different kinds of bluegreen algae that are notorious HAB-formers, including

1. This document is TP-231, one of a series of the Florida Sea Grant College Program and UF/IFAS Extension. Original publication date February 2018. Visit the EDIS website at http://edis.ifas.ufl.edu.

2. Karl Havens, director, Florida Sea Grant College Program; UF/IFAS Extension, Gainesville, FL 32611.

The Institute of Food and Agricultural Sciences (IFAS) is an Equal Opportunity Institution authorized to provide research, educational information and other services

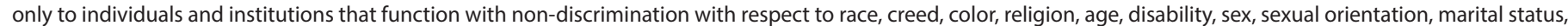

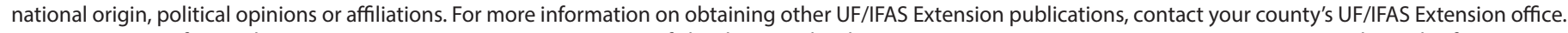
U.S. Department of Agriculture, UF/IFAS Extension Service, University of Florida, IFAS, Florida A \& M University Cooperative Extension Program, and Boards of County Commissioners Cooperating. Nick T. Place, dean for UF/IFAS Extension. 
Microcystis, Anabaena, and Cylindrospermopsis. Many of these algae produce toxins that can kill fish, wildlife, and even domestic animals that come into contact with the water near the lake shore. Harmful algal blooms also have the potential to cause liver cancer or nervous system problems in people who are exposed to the water over a long period. For example, people who obtain drinking water from a lake with frequent HABs have become ill. Those conditions are not common in Florida because most people get their drinking water from the underground aquifer.

In the ocean and nearshore coastal waters, HABs are most often caused by a kind of algae called a dinoflagellate. One of these, Karenia brevis, causes red tides (Figure 2) that are common along the Florida coast in the Gulf of Mexico. Red tides produce toxins that cause fish kills and can cause respiratory distress in swimmers and people on the beach when the blooms are near to the shore. Other kinds of dinoflagellates cause HABs in Atlantic coastal waters.

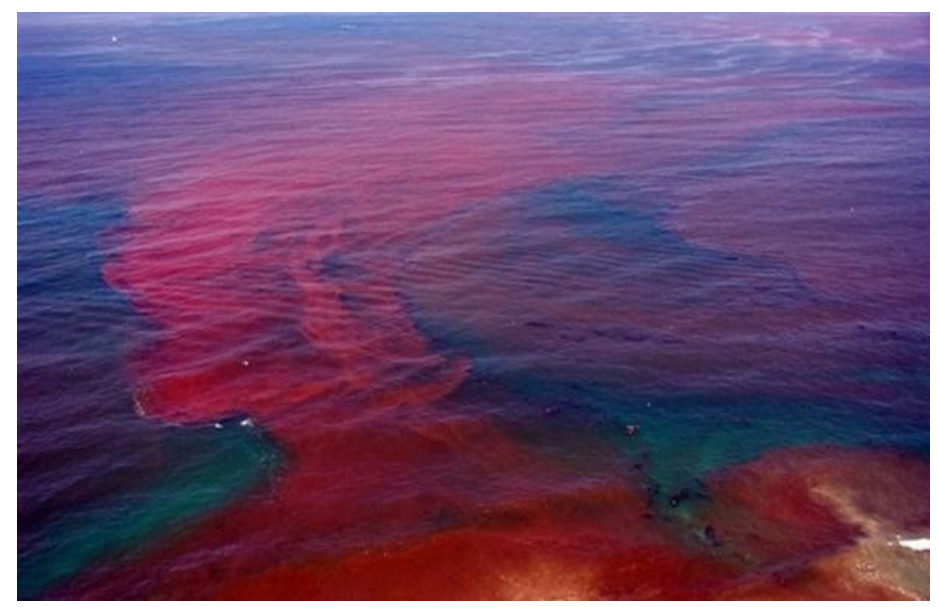

Figure 2. Harmful algal blooms in the ocean, often called red tides, can cause fish kills and respiratory distress to nearby people, even when the bloom is not as intensely colored as this example, shown to illustrate where the blooms get their name.

Credits: Kai Schumann, California Department of Public Health volunteer

In recent years, there have been HABs comprised of various kinds of algae in Biscayne Bay, the Indian River Lagoon, the St. Lucie Estuary, Lake Okeechobee, and the Caloosahatchee Estuary. Figures 3 and 4 show a blue-green HAB that started in Lake Okeechobee, migrated to the St. Lucie River, and ended up on the beaches of Stuart in the summer of 2016.

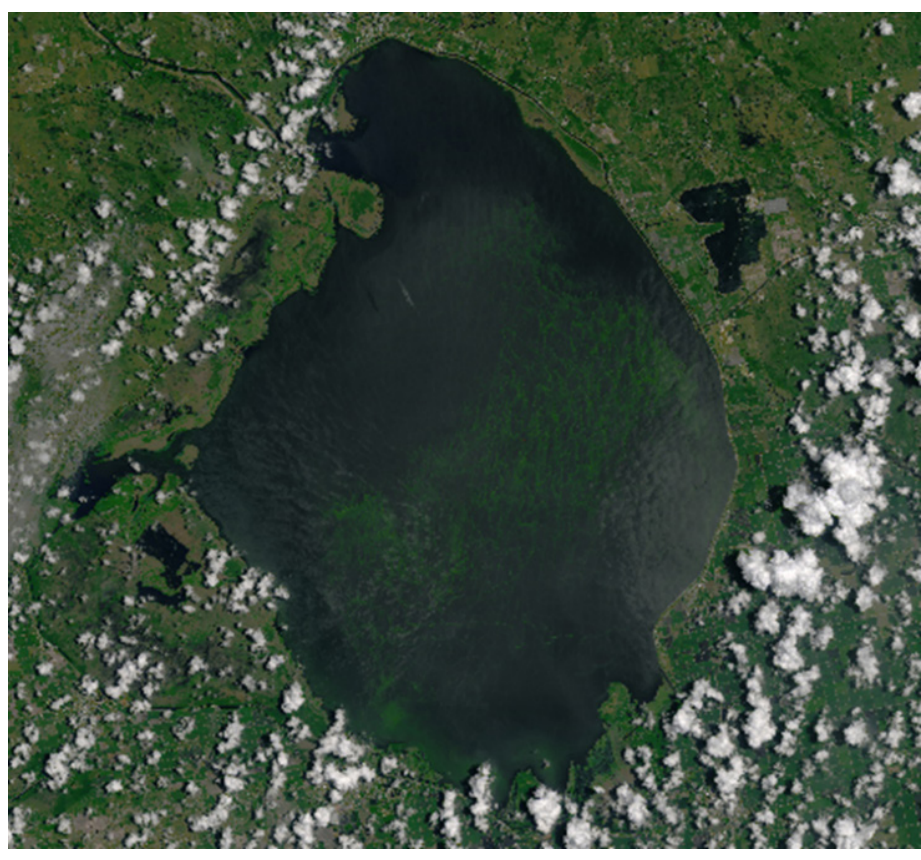

Figure 3. A large bloom of Microcystis, a kind of blue-green algae, covered nearly 60 percent of the surface of Lake Okeechobee in summer 2016.

Credits: NASA Earth Observatory

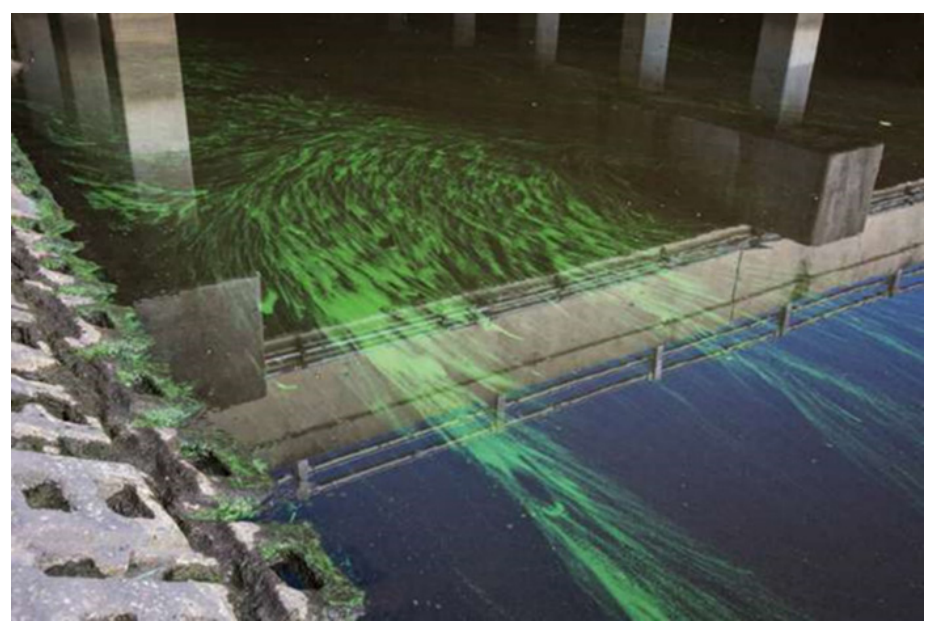

Figure 4. In summer 2016, the Microcystis from Lake Okeechobee was carried downstream in the St. Lucie River to the estuary. Here we can see water flowing under a highway bridge with bright green algae on the surface. The top edge of the bridge is reflecting in the water. Credits: Ed Phlips, UF/IFAS

\section{What causes harmful algal blooms?}

The factors causing a HAB occur at three levels. At the first level, a lake, reservoir, or estuary develops underlying conditions that are favorable to blooms. Those include high concentrations of nutrients (nitrogen and phosphorus in particular), adequate light, and, generally, warm water. These conditions set the stage for HABs to occur. 
At the second level, additional factors occurring on a shorter time-scale make it even more likely that HABs will happen or that HABs will be more severe. For example, in Lake Apopka and the other shallow lakes near Orlando, it has been documented that HABs are most severe in periods of drought. This is because the nutrients in the water are concentrated when the volume of the lakes is lower and the fish stir up more sediments. There is also a greater amount of light available in the water to fuel algal growth. Large HABs in Lake Okeechobee have consistently happened during the summer one year after there was unusually heavy rainfall and large nutrient transport into that lake from the watershed.

At the third level, when all of the conditions above are just right, there are short-term triggers that can start HABs. The triggers could include a week of calm weather, which allows certain types of HABs to form just below or on the water surface, or some very hot sunny days without cloud cover. Conversely, an intense rain event or a couple of overcast days might end a particular $\mathrm{HAB}$ event even when the underlying conditions are still good for algae growth.

Scientists have a good understanding of how the first and second-level conditions described above affect HAB formation. They also understand how the third level, shortterm triggers work. However, because those triggers are unpredictable, it remains difficult for scientists or resource managers to know when a particular HAB event will start and how long it will last in a body of water. Given two HABs of the same intensity, one might last one week if a heavy rainstorm happens and mixes up the water; the other could last a month if conditions remain calm and sunny for that long.

In the marine environment, predicting HABs is even more challenging. While it is clear that the algae that cause red tides require nutrients and light in order to grow to a level where they cause an $\mathrm{HAB}$, the triggers for a particular $\mathrm{HAB}$ are not well understood. Scientists continue to debate about the degree to which red tides happened historically, before coastal waters were polluted by nutrients derived from human activities.

\section{How might climate change affect HABs?}

Scientists predict there will be increases in global temperatures and weather extremes caused by climate change. As discussed earlier, both the temperature of water and the amount of nutrients in that water can affect the occurrence and intensity of blooms. However, the relationship is complicated. When nutrient levels are low, rising water temperature results in just a small increase in the occurrence of algae that form HABs. On the other hand, when nutrient levels are high-in the range that we commonly see today in lakes such as Okeechobee and Apopka and in estuaries such as the St. Johns and Indian River Lagoonincreases in temperature of just a few degrees result in exponential increases in occurrence of the $\mathrm{HAB}$-forming types of algae.

Scientists are also discovering that the intensity of HABs in lakes is influenced by drought, citing examples from around the world. Here in Florida, cyanobacteria blooms are as much as five times as intense in drought years as in wet years in lakes north of Orlando, including in Lake Apopka. It is expected that in the future, climate change will result in longer-lasting droughts, and this could exacerbate HABs in lakes and reservoirs.

The effects of climate change are a challenge for those who aim to control HABs. It means that actions now to reduce nutrient concentrations are likely to be much more successful than the same amount of nutrient reduction in 20 or 50 years, when the temperature of the water will be higher. Water temperatures in lakes already have increased since the end of the $20^{\text {th }}$ century, so it is not just a future issue but a problem that is of concern now.

\section{What are solutions?}

The most direct way communities can solve a problem with $\mathrm{HABs}$ is to take action to reduce nutrient inputs to estuaries, the coastal ocean, lakes, and rivers before warming and changes in drought intensity and duration make it nearly impossible to control HABs. Traditional measures to reduce nutrients include:

- switching old neighborhoods from septic to central sewage;

- reducing the use of fertilizer to recommended levels on crops or capturing and cleaning the runoff water from those lands;

- controlling the export of nutrients in manure from animal agriculture; and

- making changes to land use, including in residential neighborhoods, to replace plants that require the addition of nutrients with species of plants that are adapted to grow in Florida soil.

In the case of large lakes in Florida such as Apopka and Okeechobee, traditional measures have not been successful. Despite a concerted effort dating back to the 1970s and 
involving a considerable number of programs to control nutrients entering Lake Okeechobee, the input of nutrients to that lake has not changed. In fact, the concentration of nutrients in the lake water has actually increased. Similarly, over the past 20 years, the nutrient level and HAB occurrence in Lake Apopka have not declined, despite large efforts to reduce nutrient inputs from the watershed and from the sediments at the bottom of the lake. Paraphrasing an old saying, tough times call for tough measures, and this might apply to these large, shallow lakes. Removing those nutrients will be tremendously expensive, and the engineering will be highly challenging, yet the benefits over the long term could far outweigh the costs. Despite its cost, sediment removal might need to be considered for $\mathrm{HAB}$ remediation. If we do not find a method that effectively limits nutrient concentrations in large, shallow lakes, HABs in these lakes will continue to be controlled by weather, droughts, and rising air and water temperature-all factors that are not under our control.

On the other hand, in smaller bodies of water, especially those that have not been polluted by nutrients for a long period of time, smaller, less expensive actions by individuals, neighborhoods, and towns can have a positive impact. Across Florida, many homeowner associations have been able to control HABs in their small lakes and ponds by reducing the use of fertilizer on grassy areas around the water and on their lawns, and by planting native vegetation to create a buffer strip in the shorelines around the water. The town of Tequesta greatly improved water quality in a portion of the Loxahatchee River when property owners switched from septic tanks to a central sewerage system. There is a wealth of information about how you and your neighbors can reduce nutrient inputs to fresh waters and coastal waters from your local UF/IFAS Extension office, on the UF/IFAS EDIS website, and in the Florida Sea Grant publication A Practical Guide to Estuary-Friendly Living (SGEB-64) (http://nsgl.gso.uri.edu/flsgp/flsgph12001.pdf).

\section{Further information}

Florida Fish and Wildlife Commission. "Red Tides." http:// myfwc.com/research/redtide/

Havens, K. E. 2012. Effects of climate change on the eutrophication of lakes and estuaries. SGEF-189. Gainesville: University of Florida Institute of Food and Agricultural Sciences and Florida Sea Grant College Program. http:// edis.ifas.ufl.edu/sg127

Havens, K. E. 2015. Climate change and the occurrence of harmful microorganisms in Florida's ocean and coastal waters. SGEF216. Gainesville: University of Florida Institute of Food and Agricultural Sciences and Florida Sea Grant College Program. http://edis.ifas.ufl.edu/sg136

Havens, K. E., and T. Frazer. 2012. Rethinking the role of nitrogen and phosphorus in the eutrophication of aquatic ecosystems. SGEF-190. Gainesville: University of Florida Institute of Food and Agricultural Sciences and Florida Sea Grant College Program. http://edis.ifas.ufl.edu/sg118

Havens, K. E., M. V. Hoyer, and E. J. Phlips. 2016. Natural climate variability can influence cyanobacteria blooms in Florida Lakes and Reservoirs. SGEF-234. Gainesville: University of Florida Institute of Food and Agricultural Sciences and Florida Sea Grant College Program. http:// edis.ifas.ufl.edu/sg142

Havens, K. E., G. Ji, J. R. Beaver, R. S. Fulton III, and C. E. Teacher. 2017. "Dynamics of cyanobacteria blooms are linked to the hydrology of shallow Florida lakes and provide insight into possible impacts of climate change." Hydrobiologia, DOI: 10.1007/S10750-017-3425-7

Havens, K. E., and H. W. Paerl. 2015. "Climate change at a crossroad for control of harmful algal blooms." Environmental Science and Technology, DOI 10.1021/acs. est.5b03990.

Paerl, H. W., W. S. Gardner, K. E. Havens, A. R. Joyner, M. J. McCarthy, S. E. Newell, B. Qin, and J. T. Scott. 2015. "Mitigating cyanobacterial harmful algal blooms in aquatic ecosystems impacted by climate change and anthropogenic nutrients." Invited Review, Harmful Algae, Online: http:// dx.doi.org/10.1016/j.hal.2015.09.009

Paerl, H. W., T. Scott, M. J. McCarthy, S. Newell, W. S. Gardner, K. E. Havens, W. Wurtsbaugh, and S. W. Wilhelm. 2016. "It takes two to tango: why dual nutrient (N\&P) reductions are now the rule rather than the exception for eutrophication and harmful algal bloom control along the freshwater to marine continuum." Environmental Science and Technology, DOI 10.1021/acs.est.6b02575. 